\title{
Microhabitat specialisation and ecological consequences for coral gobies of the genus Gobiodon in the Gulf of Aqaba, northern Red Sea
}

\author{
Markus Dirnwöber ${ }^{1}$, Jürgen Herler ${ }^{2, *}$ \\ ${ }^{1}$ Department of Marine Biology, and ${ }^{2}$ Department of Theoretical Biology, Morphology Section, Faculty of Life Sciences, \\ University of Vienna, Althanstrasse 14, 1090 Vienna, Austria
}

\begin{abstract}
The microhabitat selection and distribution of 6 coral-associated species of Gobiodon were examined in the Gulf of Aqaba, northern Red Sea, including 3 recently discovered species. A total of 1626 fishes were counted visually using $10 \times 1 \mathrm{~m}$ belt transects in 1731 colonies of 13 species of Acropora. Niche segregation was observed at the level of coral species. Gobiodon sp. 2 was the most specialised, occupying only A. hyacinthus; Gobiodon sp. 1 was most generalised (occupying 3 species of Acropora more frequently than expected). G. reticulatus was a zone specialist that preferred deeper water regions. Less specialised species were able to use substitute host corals, which enabled them to maintain extraordinarily high abundance. G. histrio, for example, preferred the rare A. digitifera, but was common in the very abundant A. acuminata, although proportionally fewer breeding pairs were established in the latter. When compared to the western Pacific, G. histrio showed a more generalised behaviour in the northern Red Sea, and different coral species served as host corals; the latter also holds true for the even more generalised G. rivulatus. Hence, species of Gobiodon appear to alter host-use and degree of specialisation on a global scale.
\end{abstract}

KEY WORDS: Gobiodon spp. · Acropora spp. · Gobiidae ' Habitat associations · Abundance · Reef fish $\cdot$ Coral reefs $\cdot$ Red Sea

- Resale or republication not permitted without written consent of the publisher

\section{INTRODUCTION}

Microhabitat specialisation is common among small coral reef fishes such as pomacentrid, apogonid, pseudochromid, or gobiid species and is often found at the level of coral species (Munday et al. 1997, Gardiner \& Jones 2005). These fishes are therefore highly dependent upon the cover, diversity and complexity of the respective habitat, and natural or anthropogenic impacts will affect their populations (Jones \& Syms 1998, Jones et al. 2004, Graham et al. 2006). The degree of microhabitat specialisation is likely to be an important factor influencing the abundance and geographic distribution of species (Brown 1984, Brown et al. 1995, Jones et al. 2002, Munday 2002). Most studies of these relationships, however, have been carried out at a few Indo-Pacific sites (Munday 2002, Gardiner \&
Jones 2005), and little is known about how this dependence on habitat structure varies in different geographic regions. Coral diversity and abundance strongly influence associated reef fishes, especially when there is strong interspecific competition for limited habitats. Competition among coral reef fishes with similar ecological demands may reduce the abundance and change the patterns of microhabitat choice of especially inferior competitors (Robertson 1996, Munday et al. 2001), while habitat availability may alter these patterns even in superior competitors (Munday 2002).

The Red Sea is an appropriate region to study such geographical differences, because, although it belongs to the western Pacific/Indian Ocean reef province, it is largely isolated, has a unique fauna and also high degrees of endemism among many reef organisms 
(Head 1987). It is characterised by well-developed coral reefs, but a reduced biodiversity of hermatypic corals compared to the eastern Indian or western Pacific Ocean (Veron 2000). A key question that can be posed is: How does the level of reef fish specialisation or dependence upon coral differ in a region of reduced coral diversity? Suitable reef fishes to examine this question need to: (1) exhibit specific microhabitat selection that can be easily investigated and quantified and (2) have a wide distribution area to allow comparable studies at the species level on a global scale. Such requirements are fulfilled by a series of coralassociated gobiid fishes.

Coral-dwelling gobies belong to the most specialised reef fishes and are good study models because they show distinct microhabitat choices at the level of coral species. Due to their small body size and the high structural variation among hard corals, these fishes can potentially occupy a broad range of microhabitats (Munday et al. 1997). Coral-associated species belong to the genera Gobiodon, Paragobiodon, Bryaninops, or Pleurosicya (Herler 2007). Although these fishes are difficult to study, detailed ecological studies on their habitat preferences hold the key to understanding the population dynamics, distribution and evolution of small reef fishes with strong habitat fidelity (Kuwamura et al. 1994, Munday et al. 1997, 2001), especially for species associated with living hosts. The degree of habitat specialisation among Gobiodon spp. was revealed by Munday et al. (1997), who showed that species distribution is disproportional among the various Acropora spp. at the Great Barrier Reef (GBR). This makes them optimally suited to study variation of patterns of distribution and abundance.

Most studies on the ecology of Gobiodon spp. focused on the tropical Indo-West Pacific region rather than on the Red Sea, which is the north-western boundary of their distribution. Acropora is represented in the Red Sea by about 40 species (Wallace 1999), and Acropora diversity at single reefs can drop down to $<15$ species (J. Herler \& M. Dirnwöber pers. obs.). In contrast, local diversity of potential host corals of the genus Acropora was much higher on western Pacific reefs, e.g. at Lizard Island (GBR, Australia) (Munday et al. 1997). Similarly, reef fish diversity is lower in the Red Sea (Bellwood \& Wainwright 2002). Among Gobiodon spp., only 4 species were known from the Red Sea prior to our studies: G. citrinus (Rüppell, 1838), G. histrio (Valenciennes, 1837), G. rivulatus (Rüppell, 1830) and G. reticulatus Playfair, 1867. Three additional species were recently discovered as new records for the Red Sea and are probably even new to science, but of questionable taxonomic status (Herler \& Hilgers 2005).

The abundance of Gobiodon spp. is usually limited by host coral abundance (Munday 2000), and intensive competition is the norm, especially for those coral species used by $>1$ Gobiodon spp. (Munday et al. 2001, Hobbs \& Munday 2004). Occupation rates of approximately $80 \%$ have been reported among certain species of Acropora (Munday et al. 1998), while highly preferred Acropora spp. - like A. nasuta-reach occupation rates of almost $100 \%$, especially among the larger colony size classes (Hobbs \& Munday 2004). These high occupation rates limit the opportunities for juveniles and inferior competitors to settle. Munday et al. (2001) demonstrated that species can coexist by diverse mechanisms. The various adaptations that structure this coral-dwelling community will depend on the number and species of Gobiodon inhabiting a region and the availability and diversity of suitable coral colonies. At geographical scales, e.g. between the GBR and Papua New Guinea (PNG), habitat use by certain Gobiodon spp. differed. Other species, such as G. histrio, for example, exhibited a very conservative pattern of habitat use on such a scale (Munday et al. 1997, Munday 2002).

The present study investigates the local diversity, abundance and microhabitat selection of Gobiodon spp. with respect to the availability of potential host corals in the northern Red Sea. We also examine whether habitat choice patterns are retained at larger geographic levels depending on the presence of host corals. We provide the first data on microhabitat selection and niche segregation of a guild of coral-gobies in the Red Sea. This, in turn, allows insights into changes in the ecology of certain species on a global spatial scale, when we compare our results with previously published data (Munday et al. 1997, Munday 2002). We tested the following hypotheses for small reef fishes: (1) species of a guild of habitat-specialised fishes differ in their microhabitat choice (host coral selection), as assumed by Munday et al. (1997); (2) the degree of specialisation differs among coral-associated conspecifics (Munday et al. 1997) and explains local abundance of species (Brown et al. 1995); (3) a lower coral diversity results in a less diverse community of obligate coral-associated fishes and higher specialisation (narrower spatial niche) of species; and (4) the degree of specialisation and specific host preferences may be altered over large geographical distance on, e.g., a 'global scale'.

\section{MATERIALS AND METHODS}

Study area. The study was conducted between March and June 2004 at Dahab $\left(28^{\circ} 28^{\prime} \mathrm{N}, 34^{\circ} 30^{\prime} \mathrm{E}\right)$, in the Gulf of Aqaba, northern Red Sea, Egypt (Fig. 1). To investigate the habitat preferences among the different species of Gobiodon, 2 study sites about $1 \mathrm{~km}$ apart 


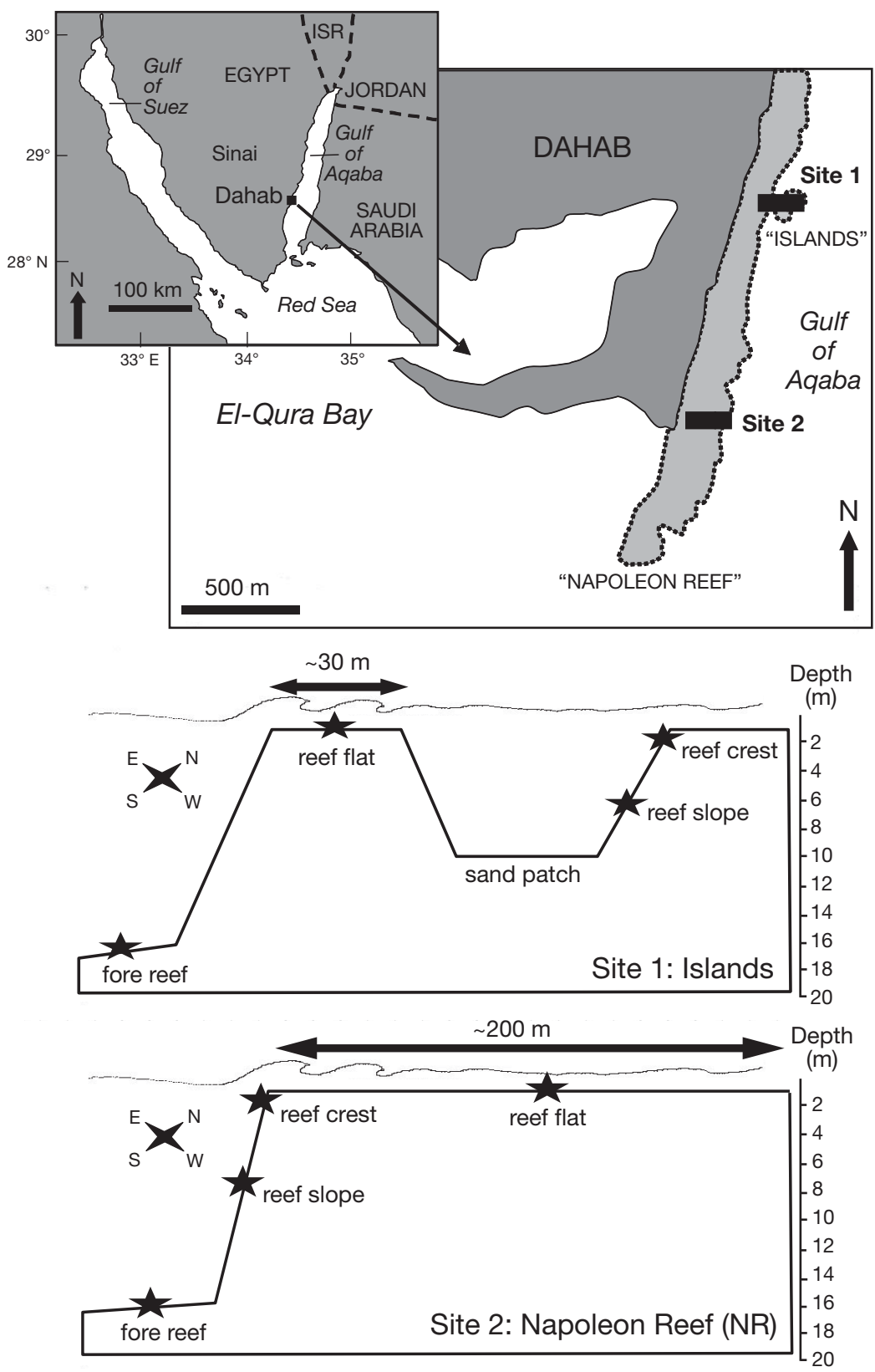

Fig. 1. Sampling sites in the vicinity of Dahab, Sinai. Inset shows Gulf of Aqaba, northern Red Sea, and the Sinai Peninsula, Egypt. The dotted line indicates the course of the reef crest and of the offshore islands. The 2 investigation sites are marked by black rectangles (upper panel). Transect positions are indicated by black stars for each site (lower panels)

were chosen (Fig. 1). The first site is known as 'Islands'; the second site was approximately $500 \mathrm{~m}$ north of the 'Napoleon Reef', at the outermost part of the promontory (Fig. 1) and will be referred to as 'NR' in the following. Both study sites had similar exposure to prevailing winds, but the inshore fringing reef of Site 1 is protected by 2 large offshore reef bodies (the 'Islands'), which reach up to the water surface; the reef flat of the inshore fringing reef is strongly eroded, with little live coral coverage. Therefore, the adjacent, wave-exposed patch reefs-offering high coral coverwere used as the reef flat zone. The reef crest and slope at Site 1, however, were less wave-exposed due to the offshore reefs. At Site 2 (NR), reef zones were more continuous, and large areas of the reef flat were less exposed due to its long horizontal extension and the dissipation of wave energy at the reef edge.

Data sampling. To determine Gobiodon spp. coral preferences, all species of Acropora were censused regardless of growth form. At each site, 5 belt transects of $10 \times 1 \mathrm{~m}$ were established in the centre of the reef flat, along the reef crest (between 1 and $3 \mathrm{~m}$ depth) and in the lower half of the reef slope (average depth about $8 \mathrm{~m}$ ). Ten transects were laid at the reef slope of Site 2 to guarantee a sufficient amount of colonies for analyses, because this reef zone had an extremely low abundance of Acropora spp. Transects were laid roughly parallel to the coast line, and the position of each transect was haphazardly selected. Each Acropora colony with a minimum diameter of $10 \mathrm{~cm}$ (necessary for reliable field identification at species level) and located more than half within the belt transects was considered. Maximum diameters were measured to the nearest $5 \mathrm{~cm}$. Colonies were carefully censused for the presence of Gobiodon spp. using an underwater torch; the identity and number of fish were recorded. Fish size was estimated in situ using a series of artificial fish templates representing $5 \mathrm{~mm}$ size classes ( $<15$ to $>40 \mathrm{~mm}$ total length). The fore reef zone of the Islands site was additionally sampled for information on deeper-living Gobiodon spp. SCUBA-diving constraints and the low and patchy coverage of Acropora spp. within the Islands fore reef required an alternate sampling design here: data were gained through random swims between 15 and $17 \mathrm{~m}$ depth. Every Acropora colony was examined as stated above, until 200 colonies had been sampled. Overall coral abundance here was subsequently estimated by counting colonies within 5 randomly laid $10 \mathrm{~m}^{2}$ belt transects. 
Coral and fish species studied. Preliminary identifications of Acropora spp. followed Wallace (1999) and Veron (2000). Representative samples of coral colonies of every species of Acropora were sent to Dr. Carden Wallace (Museum of Tropical Queensland, Townsville, Australia) for confirmation of coral identities. Samples were taken in accordance with national and international laws (NSC/EEAA and CITES-permissions from Egypt and Australia). Thirteen species of Acropora were identified during this study (Table 1).

Six species of Gobiodon inhabiting Acropora spp. were selected for this study: G. histrio (his), G. reticulatus (ret), G. rivulatus (riv), and 3 undescribed species-Gobiodon sp. 1 (sp1), Gobiodon sp. 2 (sp2) and Gobiodon sp. 3 (sp3). For detailed descriptions of the 3 latter species see Herler \& Hilgers (2005). Although G. citrinus is present in the Gulf of Aqaba (Herler \& Hilgers 2005), this species did not occur at the selected sites. Gobiodon spp. could be easily identified in situ based on their distinctive colour patterns. G. rivulatus exhibits 2 colour morphs - a light and a dark form - which have already been observed in the western Pacific (Munday et al. 1999). Both forms occurred in the Gulf of Aqaba (Herler \& Hilgers 2005) and were considered separately, as the taxonomy of this species is not yet resolved. Minimum body size for adult fish was estimated for each species after juveniles were distinguished from adult males and females by their characteristically developed genital papilla. The thresholds for total length were $25 \mathrm{~mm}$ for G. histrio and Gobiodon sp. 3, $20 \mathrm{~mm}$ for G. reticulatus, G. rivulatus and Gobiodon sp. 1, and $15 \mathrm{~mm}$ for Gobiodon sp. 2.

Table 1. Acropora spp. Species of Acropora corals investigated for microhabitat choice of Gobiodon spp. in the Gulf of Aqaba, northern Red Sea, including the total number (n) and relative percentage $(\%)$ of examined colonies and the abbreviations used in further tables and graphs

\begin{tabular}{|lrrc|}
\hline Coral & $\mathrm{n}$ & $\%$ & Abbrev. \\
\hline A. acuminata (Verrill, 1864) & 424 & 24 & acu \\
A. loripes (Brook, 1892) & 234 & 14 & lor \\
A. gemmifera (Brook, 1892) & 190 & 11 & gem \\
A. hyacinthus (Dana, 1846) & 185 & 11 & hya \\
A. secale (Studer, 1878) & 162 & 9 & sec \\
A. variolosa (Klunzinger, 1879) & 115 & 7 & var \\
A. samoensis (Brook, 1891) & 109 & 6 & sam \\
A. selago (Studer, 1878) & 90 & 5 & sel \\
A. eurystoma (Klunzinger, 1879) & 84 & 5 & eur \\
A. digitifera (Dana, 1846) & 51 & 3 & dig \\
A. humilis (Dana, 1846) & 47 & 3 & hum \\
A. squarrosa (Ehrenberg, 1834) & 34 & 2 & squ \\
A. subulata (Dana, 1846) & 6 & 0 & sub \\
Total & 1731 & 100 & \\
\hline
\end{tabular}

Statistical analyses. Chi-squared homogeneity tests were used to compare the Acropora spp. assemblage between the reef zones of both study sites. Analyses of habitat associations were conducted following Munday et al. (1997) and Munday (2000). Chi-squared goodness-of-fit tests were used to compare juvenile and adult patterns of habitat use for each species of Gobiodon, except for the dark colour morph of G. rivulatus, where juveniles were extremely rare. Chi-squared goodness-of-fit tests were also used to determine if any Gobiodon spp. used coral species disproportionately to their availability. Where Gobiodon spp. used corals disproportionately to their abundance, resource selection ratios (Manly et al. 1993) were used to determine which particular coral species was used significantly more or less frequently than expected. All species of Acropora with an abundance exceeding 10 colonies were used for statistical analyses (i.e. all coral species except $A$. subulata).

Selection ratios $\left(\omega_{i}\right)$ were estimated using the formula:

$$
\omega_{i}=o_{i} / a_{i}
$$

where $o_{i}$ is the proportion of Acropora sp. $i$ colonies occupied by a Gobiodon species of all Acropora spp. colonies occupied by this goby, and $a_{i}$ is the proportion of available Acropora sp. $i$ colonies of all available Acropora spp. colonies. Bonferroni-corrected 95 and $99 \%$ confidence intervals were estimated for each selection ratio using the formula:

$$
Z_{\alpha / 2 k} \sqrt{\left[o_{i}\left(1-o_{i}\right) /\left(u_{+} a_{i}^{2}\right)\right]}
$$

where $Z_{\alpha / 2 k}$ is the critical value of the standard normal distribution corresponding to an upper tail area of $\alpha / 2 k$, $\alpha$ equals 0.05 or $0.01, k$ is the total number of coral species and $u_{+}$is the total number of coral colonies of all species occupied by that species of Gobiodon. Definitions of $o_{i}$ and $a_{i}$ are given above. If the 95 or $99 \%$ confidence interval of the selection ratio encompassed 1 , the use of the coral species was considered to be proportional to its availability, whereas it was considered disproportionate to its availability if the confidence interval did not encompass 1 (Manly et al. 1993). A confidence interval <1 indicated that the habitat was used significantly less than expected, and a confidence interval $>1$ indicated that the habitat was used significantly more than expected. Instead of total abundance data, only the presence or absence of each Gobiodon spp. per colony was used for analyses, as recommended by Thomas \& Tyler (1990) in order to ensure independence of habitat observations. The degree of host specialisation was estimated calculating a Shannon-Wiener index $\left(H^{\prime}\right)$ for gobiid species with respect to the corals they occupied:

$$
H^{\prime}=\sum_{i=1}^{i=n}\left(\ln P_{i} \times P_{i}\right)
$$


where $P_{i}$ is the proportional use of coral species $i$ by a species of Gobiodon and $n$ is the number of coral species used.

\section{RESULTS}

\section{Habitat associations among corals and between reef zones}

\section{General distribution}

The total abundance of the 13 species of Acropora varied considerably (Table 1), and coral assemblages (Fig. 2) at the 2 sites were different at corresponding reef zones (reef flat: $\chi^{2}=282.5$, df $=11, \mathrm{p}<0.001$; reef crest: $\chi^{2}=53.5, \mathrm{df}=9, \mathrm{p}<0.001$; reef slope: $\chi^{2}=64.6$, $\mathrm{df}=6, \mathrm{p}<0.001)$. Among the 1731 coral colonies, 1626 gobies were observed (Table 1, Fig. 3). The number of coral species used by each species of Gobiodon varied, from 5 used by the most specialised species, Gobiodon sp. 2 (Fig. 3), to 12 used by the most generalistic species, Gobiodon sp. 1 (Fig. 3). Although the habitat use of juveniles differed statistically from that of adults in all species (Table 2), juveniles and adults of a particular gobiid were most often found inhabiting the same

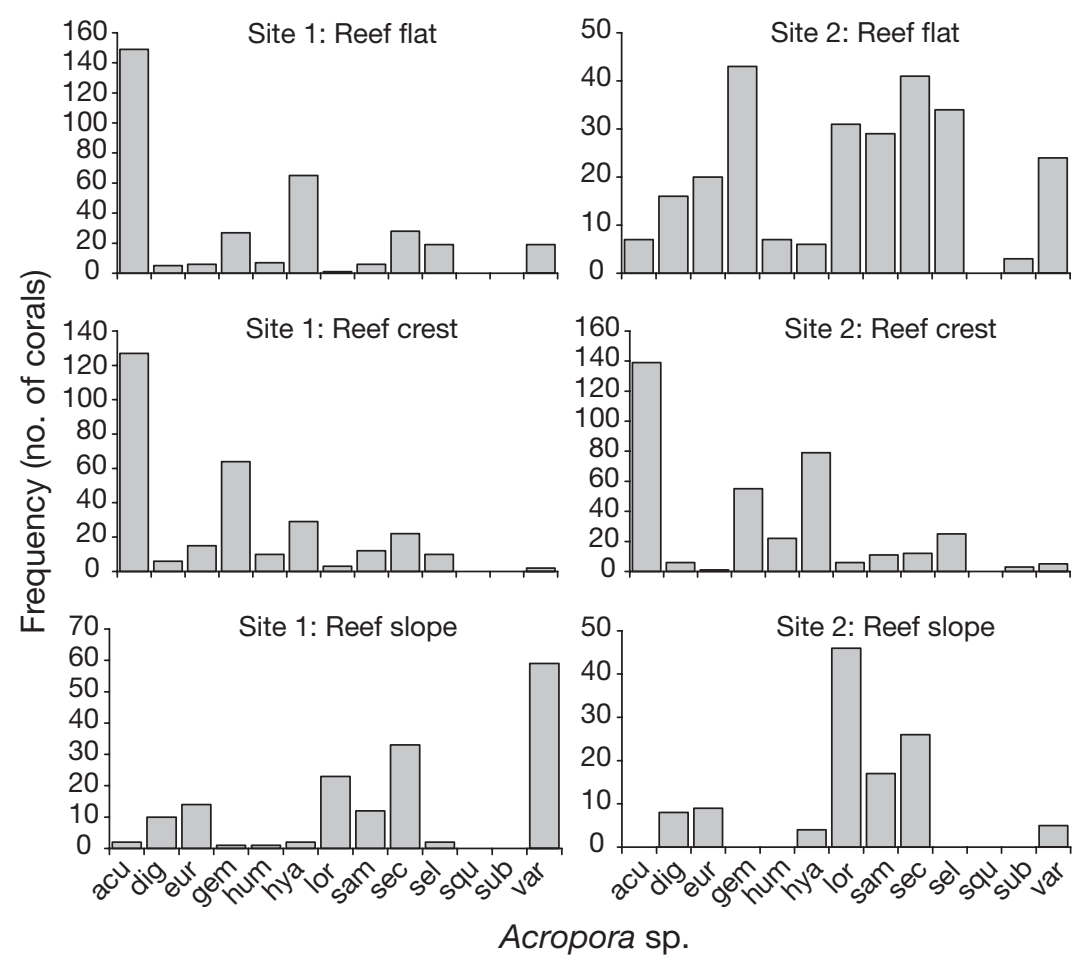

Fig. 2. Acropora spp. Frequency distributions across 3 reef zones at 2 investigation sites (Site 1: Islands, Site 2: Napoleon Reef; see Fig. 1) in the Gulf of Aqaba, northern Red Sea. Note that the number of Acropora corals at the reef slope of Site 2 comes from twice as many transects as performed in all other zones. For Acropora spp. abbreviations, see Table 1 coral species, but in different proportions (Fig. 3). Thus, the gross pattern was the same for juveniles and adults. The juvenile/adult pattern of habitat use differing most was exhibited by Gobiodon sp. 3 (Fig. 3). All Gobiodon spp. were distributed unequally over all Acropora spp. occupied (Table 2). Specialisation indices (Shannon-Wiener) varied considerably, and highly specialised species (e.g. Gobiodon sp. 2) were usually less abundant than generalised species (e.g. G. histrio, G. rivulatus, Gobiodon sp. 1). However, G. reticulatus and Gobiodon sp. 3 did not follow this trend closely.

\section{Host corals}

Resource selection ratios were calculated for each species with juveniles and adults combined (Table 3). Confidence intervals of 95 and $99 \%$ around proportions of habitats used indicated that all species of Gobiodon inhabited at least 1 coral species more frequently than expected (i.e. host coral), occurred significantly less frequently than expected in a range of coral species, and inhabited a number of other species in accordance with their availability (Table 3). G. histrio inhabited Acropora acuminata and $A$. digitifera more frequently than expected. G. reticulatus most frequently inhabited A. loripes, A. samoensis and A. squarrosa. The 2 forms of $G$. rivulatus had 2 identical host corals (A. acuminata and $A$. secale), but with opposite levels of significance. Gobiodon sp. 1 had 3 host coral species: A. gemmifera, A. samoensis and A. secale. Gobiodon sp. 2 was most specialised and most frequently inhabited A. hyacinthus. Gobiodon sp. 3 inhabited A. selago more frequently than expected.

\section{Reef zones}

All Gobiodon spp. showed their maximum abundance on the reef crest, except for $G$. reticulatus (fore reef; Fig. 4). Within that deeper zone, the diversity and abundance of Acropora spp. is comparatively low and no other Gobiodon spp. were found except for a few Gobiodon sp. 1 and G. rivulatus. A separate analysis of the fore reef zone revealed that $G$. reticulatus inhabits all abundant corals there in accordance with their availability, without favouring certain coral species. 


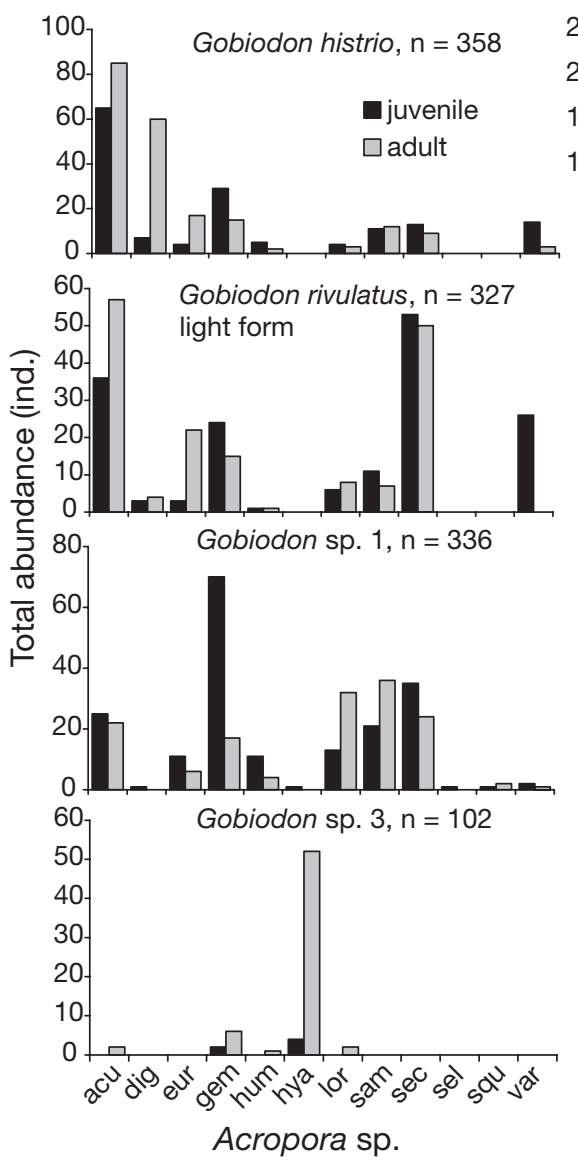

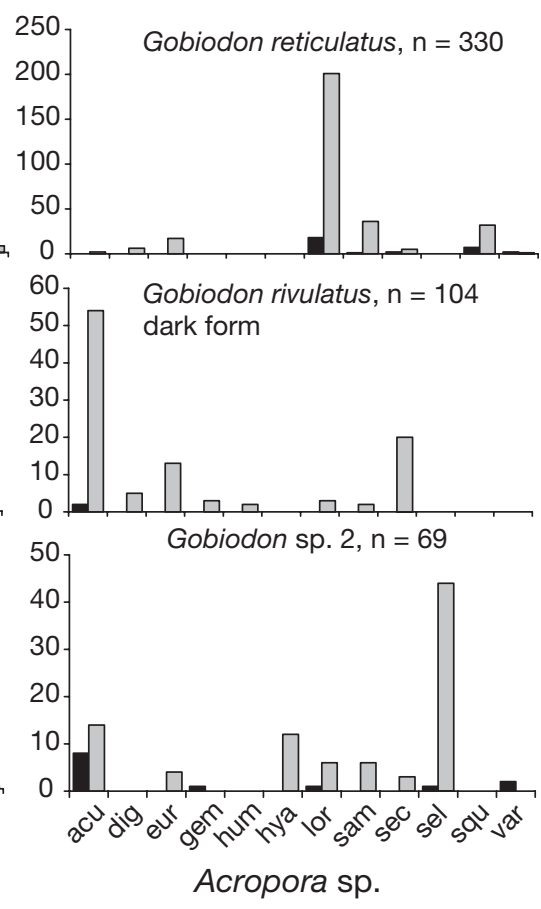

Fig. 3. Gobiodon spp. Total number of recorded specimens from each species of coral goby among all Acropora coral species in the Gulf of Aqaba, northern Red Sea. For Acropora spp. abbreviations, see Table 1

abundance was not affected: this goby occupied about $90 \%$ of the available $A$. digitifera colonies. The few individuals on the reef slope were found in this coral (yet with only $50 \%$ occupancy of the available $A$. digitifera colonies). It used $A$. acuminata as an additional host coral. Even in shallow and sheltered reef zones like the reef flat at NR, where the abundance of both host corals was very low, G. histrio maintained high abundance through inhabiting a range of other coral species according to their availability. The proportion of adult breeding pairs varied within the 2 host-coral species: approximately $70 \%$ of all occupied A. digitifera versus about $30 \%$ of all occupied A. acuminata colonies.

Gobiodon reticulatus inhabited almost only the deeper and, hence, calmer reef zones (reef slope and fore reef) and was completely absent in turbulent water regardless of the distribution of its host corals (Fig. 5c,d). Only the sheltered reef flat at NR yielded a few individuals in the host coral Acropora loripes.

The light form of Gobiodon rivulatus was more strongly associated with the abundance of 2 of its host corals (Acrop-

\section{Relation between abundance of Gobiodon and Acropora host corals}

Gobiodon histrio inhabited the reef flat and the reef crest, with only a few individuals on the reef slope (Fig. 4). It was most abundant in more sheltered and shallow reef zones, i.e. the reef crest at Islands and the reef flat at NR (Fig. 5a,b). Although its host coral Acropora digitifera was rare at the shallow zones, G. histrio ora secale and $A$. eurystoma) than with the third ( $A$. acuminata) (Fig. 5e,f). Peak abundance was recorded on the reef slope at the Islands, although $A$. acuminata was absent. At NR, the maximum abundance shifted to the reef crest zone in accordance with $A$. acuminata abundance; the significant preference for this coral mainly reflects the results from this zone. The dark colour morph of $G$. rivulatus was more closely associated with $A$. acuminata than with $A$. secale abundance.

Table 2. Gobiodon spp. Chi-squared goodness-of-fit tests for 6 species of coral gobies (light and dark morphs of G. rivulatus are treated separately) from the Gulf of Aqaba, northern Red Sea (for testing differences between juvenile and adult habitat choice and whether species are distributed unequally over all available Acropora corals); specialisation indices (Shannon-Wiener $H^{\prime}$ : the lower the index, the higher the specialisation); and total number (n) of individuals. Calculations are made for juveniles and adults combined from all 4 reef zones

\begin{tabular}{|c|c|c|c|c|c|c|c|c|}
\hline & \multicolumn{3}{|c|}{ Juvenile vs. adult habitat } & \multicolumn{3}{|c|}{ Distribution over Acropora } & \multirow[t]{2}{*}{$H^{\prime}$} & \multirow[t]{2}{*}{$\mathrm{n}$} \\
\hline & $\chi^{2}$ & $\mathrm{df}$ & $\mathrm{p}$ & $\chi^{2}$ & $\mathrm{df}$ & $\mathrm{p}$ & & \\
\hline G. histrio & 91.7 & 8 & $<0.001$ & 932 & 8 & $<0.001$ & 1.75 & 358 \\
\hline G. reticulatus & 24.9 & 4 & $<0.001$ & 4189 & 7 & $<0.001$ & 1.15 & 330 \\
\hline G. rivulatus (light) & 109.1 & 8 & $<0.001$ & 624 & 8 & $<0.001$ & 1.78 & 327 \\
\hline G. rivulatus (dark) & - & - & - & 1258 & 7 & $<0.001$ & 1.41 & 104 \\
\hline Gobiodon sp. 1 & 54.5 & 8 & $<0.001$ & 1858 & 11 & $<0.001$ & 1.93 & 336 \\
\hline Gobiodon sp. 2 & 49.7 & 5 & $<0.001$ & 2471 & 4 & $<0.001$ & 0.79 & 69 \\
\hline Gobiodon sp. 3 & 227.9 & 8 & $<0.001$ & 1606 & 8 & $<0.001$ & 1.71 & 102 \\
\hline
\end{tabular}


Table 3. Gobiodon spp. Significance of habitat use by 6 species (light [riv] and dark [riv-d] morphs of G. rivulatus are treated separately) of coral gobies (juveniles and adults combined) in the Gulf of Aqaba using resource selection ratios and Bonferroni corrected 95 and $99 \%$ confidence intervals. U: habitat unused; NS: not significant $(\alpha=0.05){ }_{i}{ }^{*}$ : habitat used significantly more than expected with $\mathrm{p} \leq 0.05 ;^{* *}$ : habitat used significantly more than expected with $\mathrm{p} \leq 0.01$; - : habitat used significantly less than expected $(\alpha=0.05)$. For abbreviations see 'Materials and methods' (gobies) and Table 1 (corals), respectively

\begin{tabular}{|c|c|c|c|c|c|c|c|}
\hline \multirow{2}{*}{ Corals } & \multirow[b]{2}{*}{ his } & \multicolumn{4}{|c|}{ Coral gobies } & \multirow[b]{2}{*}{$\mathrm{sp} 2$} & \multirow[b]{2}{*}{ sp3 } \\
\hline & & ret & riv & riv-d & $\mathrm{sp} 1$ & & \\
\hline $\mathrm{acu}$ & $* *$ & - & * & ** & - & - & NS \\
\hline dig & $* *$ & NS & NS & NS & - & $\mathrm{U}$ & $\mathrm{U}$ \\
\hline eur & NS & NS & NS & NS & NS & $\mathrm{U}$ & NS \\
\hline gem & NS & U & NS & - & ** & NS & - \\
\hline hum & NS & U & - & NS & NS & NS & $\mathrm{U}$ \\
\hline hya & U & U & U & $\mathrm{U}$ & - & ** & NS \\
\hline lor & - & ** & - & - & NS & - & NS \\
\hline sam & NS & * & NS & - & ** & U & NS \\
\hline $\mathrm{sec}$ & - & - & $* *$ & * & $* *$ & $\mathrm{U}$ & - \\
\hline sel & U & U & U & $\mathrm{U}$ & - & U & $* *$ \\
\hline squ & $\mathrm{U}$ & ** & $\mathrm{U}$ & $\mathrm{U}$ & NS & U & $\mathrm{U}$ \\
\hline var & NS & - & NS & $\mathrm{U}$ & - & U & - \\
\hline
\end{tabular}
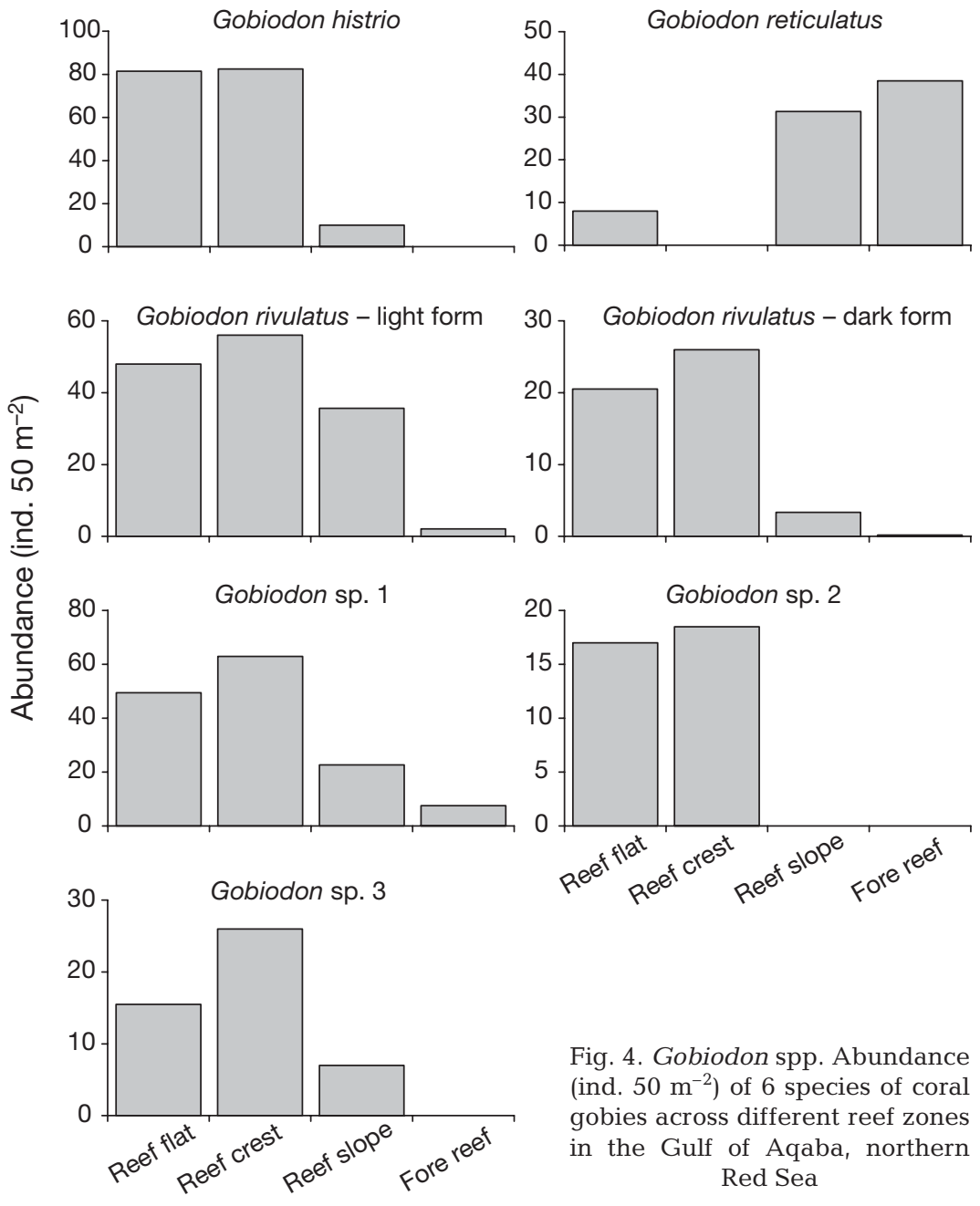

Fig. 4. Gobiodon spp. Abundance (ind. $50 \mathrm{~m}^{-2}$ ) of 6 species of coral gobies across different reef zones in the Gulf of Aqaba, northern Red Sea
In contrast to the light form, it was therefore most abundant in shallow-water reef zones and was found only occasionally on the reef slope (Figs. $4 \& 5 \mathrm{~g}$,h).

Gobiodon sp. 1 was closely associated with the abundance of its 3 host corals Acropora gemmifera, A. samoensis and $A$. secale - and with the reef crest zone at both study sites (Fig. 5i,j). Only at the calm reef flat at NR was the abundance lower than expected from habitat availability.

Gobiodon sp. 2 was closely associated with the abundance of its host coral Acropora hyacinthus (Fig. 5k,l). This coral typically inhabited turbulent and shallow reef zones and was therefore mainly distributed at the reef flat and the reef crest of the Islands site and at the reef crest of NR. Although its abundance was relatively low, the maxima of fish and host coral coincided. No individuals were found on the reef slope despite the presence of a few A. hyacinthus colonies.

Gobiodon sp. 3 was not strongly associated with the abundance of Acropora selago (Fig. 5m,n), the coral species it inhabited most frequently: while the host coral was typically most abundant at the reef flat, the fish preferred the reef crest at both study sites. However, at exposed reef zones, associations were close.

\section{Overlaps in habitat use and interspecific associations}

Together, all species of Gobiodon used a broad range of Acropora spp. as host corals (Table 3) and were found inhabiting all common species of Acropora (Fig. 3). Of the 12 corals analysed, 9 were used as hosts by the 6 gobiid species. The broad host-coral use meant overlaps of gobiid habitats (Table 3). One niche overlap occurred in $A$. secale between $G$. rivulatus (including the dark form) and Gobiodon sp. 1. The other 2 overlaps concerned A. acuminata, which was used by G. histrio and by both forms of G. rivulatus, and A. samoensis, which was used by G. reticulatus and by Gobiodon sp. 1 (Table 3). No habitat overlaps were observed for Gobiodon sp. 2 or Gobiodon sp. 3, which used only 1 coral more frequently than expected. The microhabitat choices of the light and the dark form of $G$. rivulatus were not regarded as overlaps in habitat use.

Rarely was >1 species of Gobiodon found within a single coral colony. If 

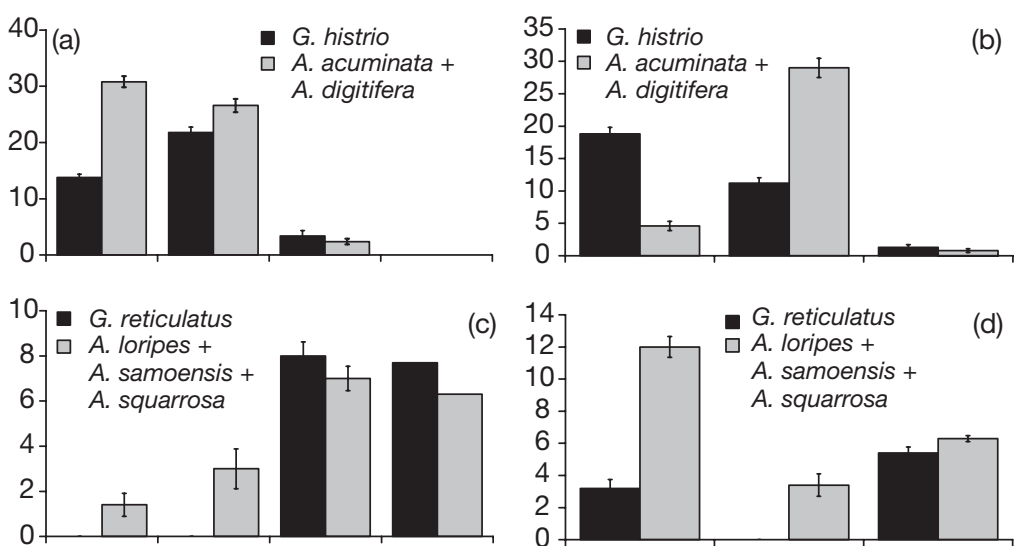

(c)
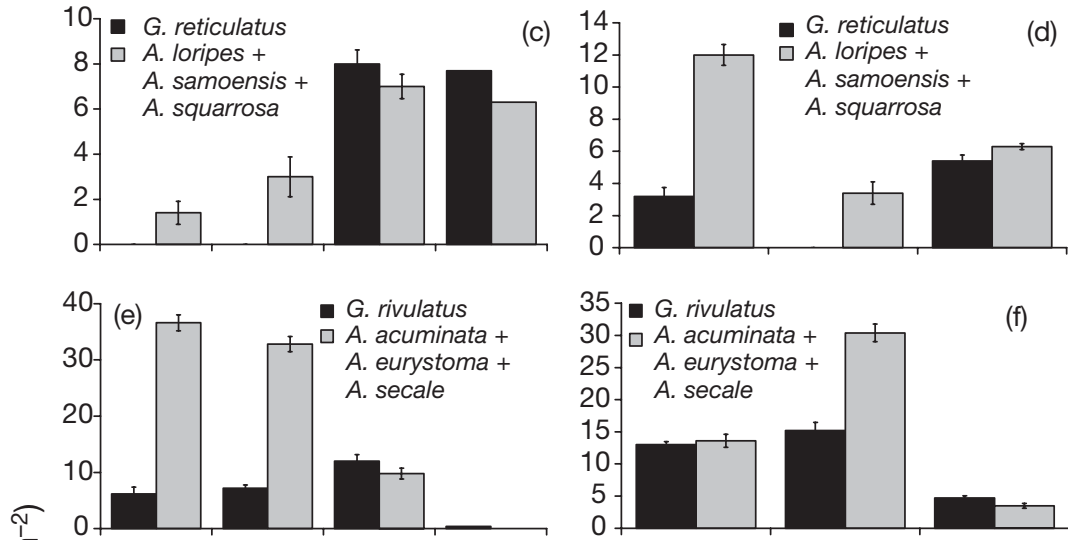

है
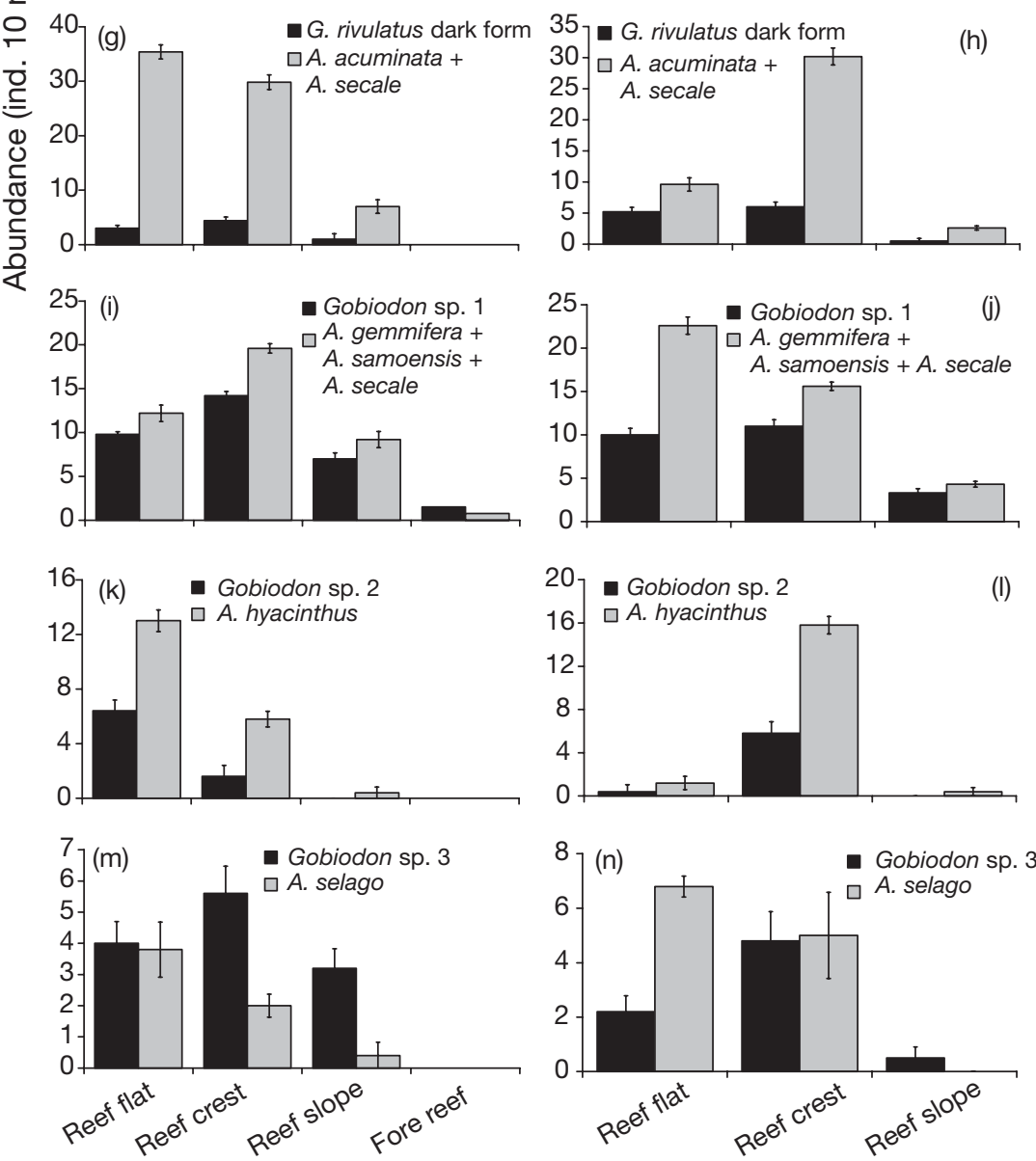

Fig. 5. Gobiodon spp. (a to n). Mean abundance ( \pm SE) per $10 \mathrm{~m}^{2}$ of coral goby species and their most frequently inhabited Acropora coral species across reef zones in the Gulf of Aqaba, northern Red Sea. Left panels: Site 1 (Islands); right panels: Site 2 (NR) associations of the dark and light forms of $G$. rivulatus are not considered as interspecific associations, such associations were only observed in $3 \%$ of all colonies. Only these cases are described in the following: it was most often observed that 2 single individuals from 2 different species shared a colony (in $40 \%$ of the cases), while associations of 2 adult breeding pairs were uncommon $(10 \%)$. In G. histrio and Gobiodon sp. 1, mostly juveniles (>70\%) were associated with other species, while, in G. reticulatus and Gobiodon sp. 3, adults dominated interspecific associations $(>80 \%)$. G. rivulatus was by far most frequently observed in associations, and slightly more adults participated. Except for the most specialised species (Gobiodon sp. 2), all species were observed in interspecific associations (Fig. 6). In all cases, 1 partner was always either G. rivulatus or Gobiodon sp. 1, and, in about half of all cases, those 2 species were found together (Fig. 6). In only 4 of all censused colonies $(=0.2 \%)$ were 3 different fish species observed. Among the coral species involved in interspecific fish associations, Acropora secale and $A$. acuminata dominated by far.

\section{DISCUSSION}

Observations of Gobiodon spp. habitat specialisations in the Gulf of Aqaba (northern Red Sea) revealed only 6 common species of this genus, reflecting a less diverse host-coral spectrum, when compared to the western Pacific (Munday et al. 1997). Most species differed in the host corals they used. Except for 1 Acropora species, all were inhabited by at least 1 Gobiodon species, and about $75 \%$ of all coral species were used as host corals, which is a much more intensive use of the available spectrum than was observed in the western Pacific by Munday et al. (1997). All species of Gobiodon occupied a range of Acropora spp., but used 1 to 3 species more frequently than expected, indicating specialisation at the level of coral species. The levels of 


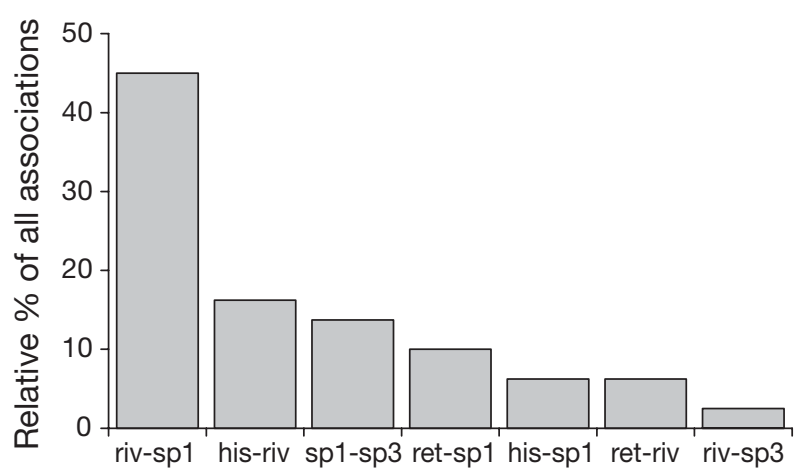

Fig. 6. Gobiodon spp. Frequency of interspecific associations of coral gobies found in colonies of different species of Acropora corals in the Gulf of Aqaba, northern Red Sea. For abbreviations of goby species, see 'Materials and methods'

specialisation and abundance varied considerably between species, and the data here support the hypothesis that specialists are less abundant than the more generalist species (Brown 1984, Brown et al. 1995). This is even indicated by the global abundance variation of a single species: the more generalistic behaviour of G. histrio in the Gulf of Aqaba is associated with a much higher abundance than in the western Pacific. Very similar abundance and specialisation values were found for G. rivulatus in both regions.

The spatial patterns of Gobiodon spp. abundances across reef zones were generally associated with the abundances of their most frequently inhabited coral species. Nevertheless, the distribution of some gobiids, like Gobiodon sp. 3, also reflected preferences for certain exposure regimes or reef zones, independent of host-coral availability. G. histrio, for example, was limited to shallow reef zones, and within these zones it was most abundant in less-exposed reef zones. There was a significant decline of Gobiodon spp. richness and abundance between the upper reef slope and the fore reef area, reflecting the very low diversity of Acropora spp. in the latter. One exception was G. reticulatus, which was most frequent in the fore reef. It extended down to a depth of $33 \mathrm{~m}$, and its maximum depth might be limited only by the depth limit of suitable Acropora spp. Compared to other Gobiodon spp., which clearly avoid competition by utilising different microhabitats, G. reticulatus shows bathymetric segregation towards an almost competitor-free reef zone. There was an inverse relation between coral abundance and occupation rates of corals, and the contribution of $G$. reticulatus to the latter varied with depth: on the reef slope, the overall occupation rate of Acropora spp. colonies was $67 \%$, but G. reticulatus contributed only $20 \%$ to this, whereas in the fore reef zone the over all occupation rate was $84 \%$ and the contribution of G. reticulatus was $68 \%$. Since G. reticulatus inhabited all abundant coral species proportionately, its population size is limited by the total abundance of colonies rather than by that of any particular coral. The high occupation rates in the fore reef yielded relatively high abundance, underlining the advantage of occupying an almost competitor-free environment.

The use of alternative microhabitats due to limited habitat availability may be a common phenomenon in both juveniles and adults. Host corals of the various Gobiodon spp. were usually dominated by breeding pairs (up to $70 \%$ in Gobiodon sp. 2 and Gobiodon sp. $3)$, with the exception of $G$. rivulatus. In species with $>1$ host coral, like G. histrio, most breeding pairs preferred 1 particular coral species. This indicates that only host corals harbouring a high percentage of breeding pairs are a primary habitat of superior competitors, in which interspecific competition plays a major role. In high-density populations, individuals may initially have to settle in suboptimal habitats (Itzkowitz 1977) and then move to better territories when they become available; this adjustment is accompanied by increased reproductive performance (Itzkowitz 1991).

Dominance hierarchies among Gobiodon spp. are largely driven by body size (Munday et al. 2001), and similar size-based dominance hierarchies have been observed in a number of site-attached reef fish species (Webster \& Hixon 2000). In the northern Red Sea, the most specialised species (Gobiodon sp. 2) was also the smallest species, ultimately making it a subordinate competitor with a small spatial niche. Its host coral was rarely used by other species. Its small body size may force it to occupy a suboptimal habitat, where negative effects on growth, survival and reproductive output become more likely (Huey 1991). However, the costs of using alternative habitats differ for competing species (Munday 2001). This would lead to a trade-off between competitive ability and fitness in alternative habitats, providing a mechanism for coexistence (Rosenzweig \& Abramsky 1997). Gobiodon sp. 2 is a habitat specialist, implying that its host coral Acropora hyacinthus (in which this goby has the lowest fitness-related costs) is a rather suboptimal habitat for most Gobiodon spp. Caley \& Munday (2003) observed that growth trades off with habitat specialisation among Gobiodon spp., and specialists avoid corals with high fitness-related costs. A. hyacinthus seems unsuitable for most other gobiid fishes and does not support large species, as is reflected in the very small size of Gobiodon sp. 2.

Although interspecific competition was largely avoided by selecting different hosts in the Gulf of Aqaba, certain overlaps in coral use occurred among Gobiodon spp. All cases of niche overlap involved only 2 of the 4 species G. histrio, G. rivulatus, G. reticulatus and Gobiodon sp. 1. Species that overlap in resources may 
not necessarily compete (Munday et al. 2001), and interspecific competition for shared host corals was variously avoided in the present study: (1) preference for an unsaturated microhabitat (coral species) that is not limited (i.e. Acropora acuminata, shared by G. histrio and G. rivulatus), (2) bathymetric segregation (in A. samoensis, shared by Gobiodon sp. 1 and G. reticulatus) and (3) tolerance (in A. secale, shared by Gobiodon sp. 1 and $G$. rivulatus, which commonly co-habited this coral).

The present study of Gobiodon spp. in the Red Sea allows us to compare microhabitat selection patterns on a global scale, at least for the widely distributed species noted in Table 4. Microhabitat choice of $G$. histrio and $G$. rivulatus (light and dark forms), for example, has also been investigated at the GBR (Munday et al. 1997) and in PNG (Munday 2000). These comparisons illustrate that microhabitat choice can vary among geographically distant regions and that modifications depend on factors like regional coral assemblages, availability of preferred host corals, and the competitive ability of a species within changing guilds. G. histrio is a superior competitor among Gobiodon spp. fishes (Munday et al. 2001), and its habitat preferences will not be significantly influenced by competitive interactions. When compared to the western Pacific, host corals were different in the Gulf of Aqaba (Table 4). Furthermore, there was less specialisation but much higher abundance observed in the Gulf of Aqaba, which is consistent with the observations of Brown et al. (1995), who proposed an inverse relationship between specialisation and abundance. The much higher abundance in the Gulf of Aqaba may also reflect the absence of competing species of a similar rank in the competitive hierarchy. In G. rivulatus, host coral species were also different in both regions, but specialisation and abundance were very similar (Table 4). G. rivulatus exhibits generalistic behaviour in all regions. Such generalisation best explains why hosts may differ between geographic locations that have significantly different Acropora spp. communities and different Gobiodon spp. guilds, affecting interspecific interactions. G. rivulatus occupied different corals at different sites and zones to achieve maximum abundance, even within 1 location in the northern Red Sea. This indicates the ability to shift to other corals if the preferred hosts become rare. Similar observations were made at the GBR, where $G$. rivulatus was abundant on the reef slope, despite the absence of its preferred host (Munday et al. 1997). Finally, the suitability of a given microhabitat can be context specific, such as when a fish inhabits a particular microhabitat only when it occurs in a particular reef area (e.g. Elliott et al. 1995). Accordingly, broad habitat choice patterns within a guild remained even at a global scale, although changes in the host-coral spectrum occurred and superior competitors became more generalised when fishes adapted to the Red Sea environment. Future research (including molecular genetics) will reveal more about the actual relationship between Red Sea and Indo-West Pacific populations.

Acknowledgements. We are grateful to M. Fouda (NCS/ EEAA) and A. Mabrouk (Nabq Managed Resource Protection Area) for research permits. M.D. is indebted to J. Ott (University of Vienna) for supervising this master thesis and for providing work space. Many thanks to $\mathrm{C}$. Wallace and $\mathrm{R}$. Winterbottom for taxonomic help with fishes and corals. P. Munday offered essential comments on an earlier draft of the manuscript, and M. Stachowitsch added linguistic corrections. Two anonymous reviewers provided very constructive criticism. A. Tischer (DAED) supported us through logistical help and provided diving and laboratory facilities. This research was funded by grants from the International Office, Vienna (M.D.), the Emil Boral foundation, Switzerland (2004) and the Austrian Academy of Sciences (APART: Austrian Programme of Advanced Research and Technology, 2005/2006) (J.H.).

\section{LITERATURE CITED}

Bellwood DR, Wainwright PC (2002) The history and biogeography of fishes on coral reefs. In: Sale PF (ed) Coral reef fishes: dynamics and diversity in a complex ecosystem. Academic Press, London, p 5-32

Brown JH (1984) On the relationship between abundance and distribution of species. Am Nat 124:255-279

Brown JH, Mehlman DW, Stevens GC (1995) Spatial variation in abundance. Ecology 76:2028-2043 
Caley MJ, Munday PL (2003) Growth trades off with habitat specialization. Proc R Soc Lond B 270:175-177

Elliott JK, Elliott JM, Mariscal RN (1995) Host selection, location, and association behaviors of anemonefishes in field settlement experiments. Mar Biol 122:377-389

Gardiner NM, Jones GP (2005) Habitat specialization and overlap in a guild of coral reef cardinalfish (Apogonidae). Mar Ecol Prog Ser 305:163-175

Graham NAJ, Wilson SK, Jennings S, Polunin NVC, Bijoux JP, Robinson J (2006) Dynamic fragility of oceanic coral reef ecosystems. Proc Natl Acad Sci USA 103:8425-8429

Head SM (1987) Introduction. In: Edwards AJ, Head SM (eds) Key environments: Red Sea. Pergamon Press, Oxford, p 1-21

Herler J (2007) Microhabitats and ecomorphology of coraland coral rock-associated gobiid fish (Teleostei: Gobiidae) in the northern Red Sea. Mar Ecol-Evol Persp (in press)

Herler J, Hilgers H (2005) A synopsis of coral and coral-rock associated gobies (Pisces: Gobiidae) in the Gulf of Aqaba, northern Red Sea. Aqua J Ichthyol Aquat Biol 10:103-132

Hobbs JPA, Munday PL (2004) Intraspecific competition controls spatial distribution and social organisation of the coral-dwelling goby Gobiodon histrio. Mar Ecol Prog Ser 278:253-259

Huey RB (1991) Physiological consequences of habitat selection. Am Nat 137:91-115

Itzkowitz M (1977) Spatial organisation of the Jamaican damselfish community. J Exp Mar Biol Ecol 28:217-241

Itzkowitz M (1991) Habitat selection and subsequent reproductive success in the beaugregory damselfish. Environ Biol Fish 30:287-293

Jones GP, Syms C (1998) Disturbance, habitat structure and the ecology of fishes on coral reefs. Aust J Ecol 23:287-297

Jones GP, Caley MJ, Munday PL (2002) Rarity in coral reef fish communities. In: Sale PF (ed) Coral reef fishes: dynamics and diversity in a complex ecosystem. Academic Press, London, p 81-101

Jones GP, McCormick MI, Sirinivasan M, Eagle JV (2004) Coral decline threatens fish biodiversity in marine reserves. Proc Natl Acad Sci USA 101:8251-8253

Kuwamura T, Yogo Y, Nakashima Y (1994) Population dynamics of goby Paragobiodon echinocephalus and host coral Stylophora pistillata. Mar Ecol Prog Ser 103:17-23

Editorial responsibility: Otto Kinne (Editor-in-Chief), Oldendorf/Luhe, Germany
Manly BFJ, McDonald LL, Thomas DL (1993) Resource selection by animals: statistical design and analysis for field studies. Chapman \& Hall, London

Munday PL (2000) Interactions between habitat use and patterns of abundance in coral-dwelling fishes of the genus Gobiodon. Environ Biol Fish 58:355-369

Munday PL (2001) Fitness consequences of habitat use and competition among coral-dwelling fishes. Oecologia 128: 585-593

Munday PL (2002) Does habitat availability determine geographical-scale abundances of coral-dwelling fishes? Coral Reefs 21:105-116

Munday PL (2004) Habitat loss, resource specialization, and extinction on coral reefs. Global Change Biol 10:1642-1647

Munday PL, Jones GP, Caley MJ (1997) Habitat specialization and the distribution and abundance of coral-dwelling gobies. Mar Ecol Prog Ser 152:227-239

Munday PL, Caley MJ, Jones GP (1998) Bi-directional sex change in a coral-dwelling goby. Behav Ecol Sociobiol 43: 371-377

Munday PL, Harold AS, Winterbottom R (1999) Guide to coral-dwelling gobies, genus Gobiodon (Gobiidae), from Papua New Guinea and the Great Barrier Reef. Rev Fr Aquariol Herpetol 26:53-58

Munday PL, Jones GP, Caley MJ (2001) Interspecific competition and coexistence in a guild of coral-dwelling fishes. Ecology 82:2177-2189

Robertson DR (1996) Interspecific competition controls abundance and habitat use of territorial Caribbean damselfishes. Ecology 77:885-899

Rosenzweig ML, Abramsky Z (1997) Two gerbils of the Negev: a long-term investigation of optimal habitat selection and its consequences. Evol Ecol 11:733-756

Thomas DL, Taylor EJ (1990) Study designs and tests for comparing resource use and availability. J Wildl Manage 54: 322-330

Veron JEN (2000) Corals of the world, Vol 1. Australian Institute of Marine Science, Townsville

Wallace CC (1999) Staghorn corals of the world: a revision of the genus Acropora. CSIRO Publishing, Collingwood

Webster MS, Hixon MA (2000) Mechanisms and individual consequences of intraspecific competition in a coral reef fish. Mar Ecol Prog Ser 196:187-194

Submitted: June 6, 2006; Accepted: December 19, 2006

Proofs received from author(s): July 2, 2007 